\title{
Prediction based charging management for full electric vehicles in a mobility-on- demand-concept using local renewable energy
}

\author{
D. Kühnert, F. Krupka and W. Schufft \\ Chair of Power Systems and High-Voltage Engineering \\ Faculty of Electrical Engineering and Information Technology \\ Chemnitz University of Technology \\ Straße der Nationen 62, 09107 Chemnitz (Germany) \\ Phone/Fax number:+0049 $37153139939 /+0049371531$ 839939, e-mail: david.kuehnert@etit.tu-chemnitz.de, \\ felix.krupka@s2006.tu-chemnitz.de
}

\begin{abstract}
Unavoidably, the aim of ecologically sustainable driving leads to the use of full electric vehicles (FEV) and a charging process based on renewable energy. Ecologically sustainable charging, however, faces a diverse range of challenges. First of all the additional integration of renewable energy sources into the distribution and regional grids requires an expansion of grid infrastructure. In addition the FEV represents a high-power load inside the electrical grid; this may cause overloads and deviations from the preset voltage band.

The management system in [1] was developed to address the problem of the high-power load as well as to maximize the usage of already available renewable energy. This paper details a charging management system which is based on [1] and incorporates the prediction of available renewable energy inside the electric grid. The management system also considers the special challenges presented by a mobility-on-demand-concept, above all the permanent availability of mobility.

First results show that the developed prediction based management system is capable to raise the percentage of renewable charging energy in comparison to a dump charging as well as to the charging management presented in [1]
\end{abstract}

\section{Key words}

Charging management, distribution grid, electric vehicles, mobility-on-demand, renewable energy

\section{Introduction}

The depletability of conventional resources [2] and the increasing concentration of greenhouse gases in the atmosphere [3] demand not only the further development of renewable sources of energy but also the efficient usage of energy. Therefore, the primary aims are the usage of energy sources based on renewable energy, the increase of efficiency and associated with these facts the reduction of emissions. Considering mobility, the best chances to fulfill these aims are located in the electric mobility.

For a higher ecological sustainability not only the average balance of renewable energy has to be considered. FEVs have to be charged at times when there is a surplus or a high capacity of renewable energy inside the grid to achieve a higher ecological sustainability than conventional vehicles. In Germany the renewable energy supply has reached the 20 percent mark in 2011 [4]. But measurement data showed that the amount of renewable energy in the considered local distribution area is much lower than average. In the considered area the percentage of renewable energy is about $7 \%$. The low amount of renewable energy would cause an unsatisfactory carbon footprint of FEVs [5]. This can be countered by a charging management that charges the FEV at times, when the percentage of renewable energy is particularly high. The developed charging management presented in [1] made it possible to increase the amount of local renewable energy up to $11 \%$ inside the examined 15-minute-steps. Considering the possibilities of predicting the renewable energy supply it would be useful to predict the charge signal to increase the amount of local renewable energy even further.

FEV, charging with more than $11 \mathrm{~kW}$, represents a highpower load in distribution grids. The distribution grids, especially the low-voltage grids $(\mathrm{Ur}=0.4 \mathrm{kV})$ in Germany are grown according to their historic current loads. Despite the high security of supply a higher number of FEVs can cause electrical problems like overloads of electrical equipment and deviations from the preset voltage band [6]. These problems can be avoided by a proper charging management [6].

This paper introduces a prediction based charging management to face the given challenges and will describe the prediction of the usage of a FEV in a mobility-ondemand-concept.

\section{The mobility-on-demand-concept "fahrE"}

The low acceptance of electric mobility is tied to the short range of electric vehicles. Studies have shown that user experience can reduce the average range preferences [7]. Mobility-on-demand-concepts are a good opportunity for users to try electric mobility. Furthermore, studies showed 
that the motorized individual mobility loses importance for many people, young people in particular. They place importance on the possibility to use available mobility [8]. These needs can be satisfied with a mobility-on-demandconcept. The research work is integrated into such a mobility concept. The concept was presented in detail in [1].

The mobility-on-demand-concept "fahrE" focuses on electric mobility and the integration of public transport. The concept is based on a station based car-sharing-system with the additional integration of other means of transport. The mobility platform connects the four locations of Chemnitz University of Technology (CUT) and includes electric bicycles, FEVs, bus, and tram. The concept will exemplarily show how companies, with more than one location in an urban area, can connect these locations using more sustainable means of transport.

\section{The charging management}

\section{A. Parameters for charging management}

The prediction based charging management is an extension of the charging management presented in [1]. This charging management was developed to charge FEV when it is ecologically sustainable without having overloads while ensuring permanent mobility. The parameters that control the charging management are shown in Fig. 1 and were explained in [1]. To predict the charge signal, the parameters have to be predicted too.

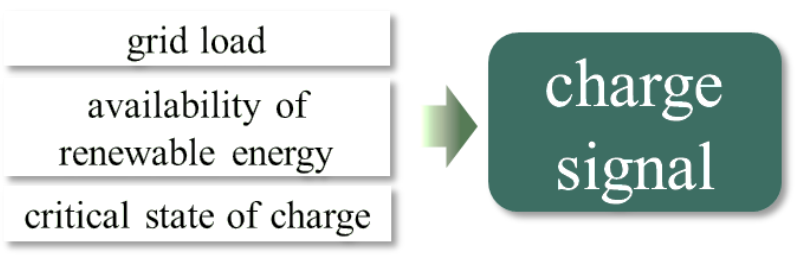

Fig. 1. Parameters of the charging management

The predictions of renewable energy supply and the load of the distribution grid are not done completely at the moment. The simulations are done with historical time series. The prediction of the critical state of charge, which is linked to the usage of a FEV in a mobility-on-demandconcept, is presented afterwards. Also the the prediction of solar irradiation is presented.

\section{B. Usage of FEV in a mobility-on demand-concept}

The mobility-on-demand concept "fahrE" uses FEVs as transport for employees of the University of Technology Chemnitz. They will enable employees to travel between different parts of the campus without having to use their own cars.

One of the goals of the charging management is to maximize the usage of renewable energy to charge the FEVs. It is easily seen that it would be useful to not only know when there is a maximum of renewable energy within the local grid but also at what times the FEV is most likely to be used. Therefore the project group designed a diary in which volunteers entered information regarding their movement habits at the university. The study was conducted in July 2012 and there were 399 participants. It could be shown that three quarters of all movements between different parts of the campus were conducted on official business, like attending a meeting, teaching or administrative functions. The most used method of transportation herby was the use of a private car with $60.8 \%$.

The original goal was to derive a statistic function from the collected movement data, with which it would have been possible to predict when a FEV was needed to substitute for a private car. That would have enabled the charging management to charge even more effectively, thus increasing the amount of renewable energy being used. Even though the examination of the collected data did not yield the wanted results, a new approach could enable the charging management to predict the usage of the FEVs.

The new approach will be working like a diary for the FEVs. In a database each use will be registered within 15minute-intervals during the working day between 6 a.m. and 8 p.m. from Monday through Friday. In the absence of precise knowledge when the FEV will be used, initially a probability of $50 \%$ will be assigned to each 15-minute interval. When the car is used an additional $10 \%$ probability will be added to the interval giving it a $60 \%$ probability in the following week. If the car is not used $5 \%$ of probability will be subtracted from the interval in question. Over a period of several weeks the charging management can learn in which time intervals there is a high probability, of the FEV actually being used. Combined with the prediction of high percentages of renewable energy in the grid; this would allow the charging management to more accurately determine when it is best to charge the FEV to maximize the use of renewable energy. The charging management could now not charge at a critical SOC because it is improbable that the FEV will be used for the next 4 intervals while there is a high amount of renewable energy predicted to occur in 2 intervals. Thus charging would be more ecological sustainable at later point of time.

\section{Prediction of solar irradiation}

The prediction of the charge signal requires that the supplied local renewable energy has to be predicted. In this paper a simple way is introduced to predict the solar irradiation.

For the charging management a method is used which is based on the persistence method. The extended persistence method [9] is able to increase the quality of prediction especially in the time horizon over 30 minutes. The charging management will predict up to two hours into future.

The method does not directly predict the irradiation; it is used to predict the clearsky-index $\mathrm{k}_{\mathrm{t}}{ }^{*}$. The clearsky-index defines the ratio between theoretically possible irradiation $\mathrm{G}_{\text {clear }}$ and measured irradiation $\mathrm{G}_{\mathrm{t}}$. $\mathrm{G}_{\text {clear }}$ is calculated by the model of [10].

$$
\mathrm{k}_{\mathrm{t}}^{*}=\frac{\mathrm{G}_{\mathrm{t}}}{\mathrm{G}_{\text {Clear }, \mathrm{t}}}
$$




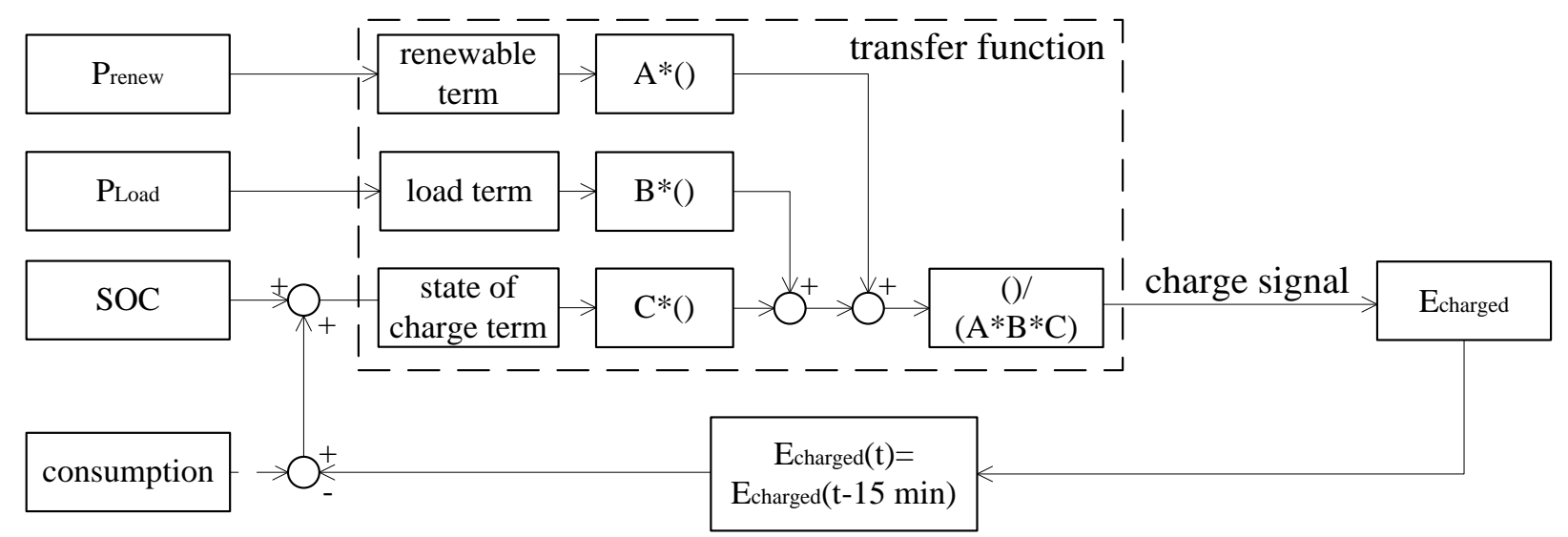

Fig. 2. Closed-loop servo system of the charging management

The disadvantage of the persistence method is that the prediction of future values is only done by the use of the last measured value. So values of short fluctuations will be assumed for the whole prediction horizon. [9] The method of exponential smoothing additionally uses historical values. The combination of these methods was used in the extended persistence method.

Basis is the average value of the last $m$ measured values of clearsky-index.

$$
\overline{\mathrm{k}}_{\mathrm{t}}^{(\mathrm{m})}=\frac{1}{\mathrm{~m}} * \sum_{\mathrm{j}=0}^{\mathrm{m}-1} \mathrm{k}_{\mathrm{t}-\mathrm{j}}^{*}
$$

The method assumes that fluctuations are primary an overshoot and the value will return to the average value. The return proceeds asymptotic for $\mathrm{t} \rightarrow \infty$.

$$
\hat{\mathrm{k}}_{\text {prog, } \mathrm{t}}^{*}=\overline{\mathrm{k}}_{\mathrm{t}}^{(\mathrm{m})}+\left(\hat{\mathrm{k}}_{\mathrm{t}}^{*}-\overline{\mathrm{k}}_{\mathrm{t}}^{(\mathrm{m})}\right) * \mathrm{e}^{-\lambda \mathrm{h}}
$$

The prediction quality can be influenced with the parameters $m$ and $\lambda$. After the prediction of the clearskyindex it will be retransformed to the predicted irradiation.

$$
\mathrm{G}_{\text {prog,t }}=\widehat{\mathrm{k}}_{\text {prog,t }}^{*} * \mathrm{G}_{\text {clear,t }}
$$

More detailed results are shown in [9].

\section{The charge signal}

The charge signal is a transfer function of a closed-loop servo system, with the influences of the three parameters, which are shown in Fig. 1. The block diagram for this function is shown at Fig. 2.

Each parameter is considered in a single function element. Every element represents a mathematic term and compares the maximum value with the current value of the parameter. The addition of all three function elements is a four-dimension characteristic map. The influence of the terms to the signal can be adjusted with weighting factors. To normalize the signal to a range between " 0 " and " 1 ", the addition result is divided by the sum of the weighting factors.

The first function element is the renewable term. This term compares the current supplied local renewable energy with the maximal potential of local renewable energy sources. The second function element, the load term, defines the influence of the load in the distribution grid. The current state of charge has an influence on the charge signal too.
It is compared with the maximum state of charge in the third function, the state of charge term.

An example of the characteristic map of the charge signal is shown in Fig. 3. The map was calculated by assuming three different grid loads. As shown, with higher loads, the signal gets lower. It is also assumed that the critical state of charge is $30 \%$ of the maximum state of charge, so the signal is set " 1 " when the state of charge falls below this value. This critical state of charge is variable and depends on the predicted usage of the FEV.

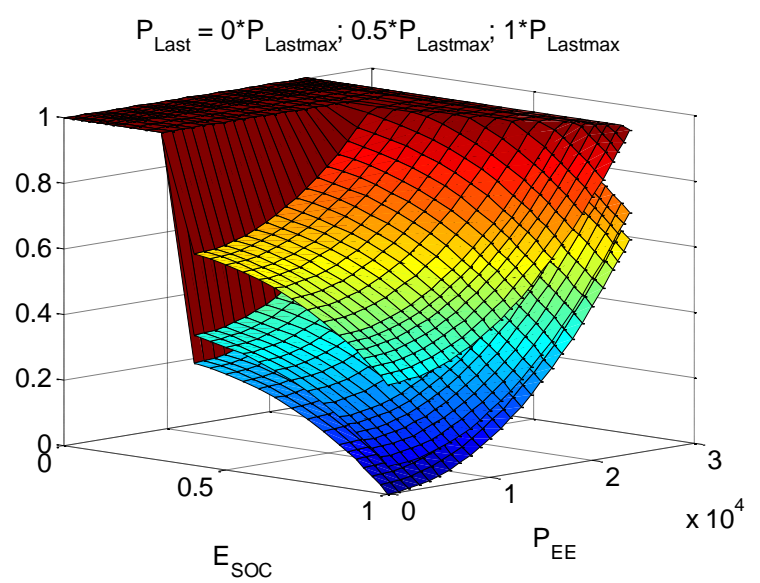

Fig. 3. Characteristic map of the charge signal

\section{E. The prediction based charging management}

The prediction based charging management uses the charge signal presented above and in [1]. The prediction of the local renewable energy sources and the usage of the FEV are done in 15-minute-time-steps up to 2 hours in the future. In the first step the charging management compares the actual state of charge with the energy which is needed to ensure mobility. When the state of charge is below the needed energy, the charge signal is set to " 1 " and the FEV will be charged immediately. Otherwise the core of the charging management will be executed. In a first step the current charge signal is calculated, as well as the predicted signals. Parallel to these calculations, the management compares the predicted state of charge and the predicted energy to ensure mobility. This comparison shows if and when the FEV has to be charged in the prediction period. This information is saved in the background.

After the calculation of the charging signals, the management system compares them. If the current signal 
is the highest one, the final signal, which is given to the FEV, is set to the current signal. When the current signal is not the highest, the management accesses the stored information, if and when the FEV has to be charged. When no charging is needed in the prediction period, the final signal will be set to "0", the FEV will not be charged. If the FEV has to be charged in the prediction period the charging management compares the current value and value of the signal at that time, when the vehicle has to be charged. If the current signal value is higher than the value at the time when the FEV has to be charged, the final signal is set to the current value. Otherwise the final signal is also set to " 0 ". These comparisons ensure that the charging is deferred to times, when charging is ecologically more sustainable or less stressful for the distribution grid.

Finally, the final signal is given to the FEV, which will charge if the signal is above " 0.5 " and will not charge if the signal is below " 0.5 ".

\section{Results}

\section{A. Simulation setting}

The simulation is done for 15 minute time intervals over a period of one year. The simulation uses measured data of wind speed, irradiation and the total load curve of the examined area. The consumption of the FEV is assumed to be $15.5 \mathrm{kWh} / 100 \mathrm{~km}$. The usage is simulated with the examined data described above. For the simulation of a FEV, a smart fortwo electric drive is selected, which will also be used in the mobility-on-demand-concept "fahrE". The smart allows charging the $17.6 \mathrm{kWh}$ battery with a power up to $22 \mathrm{~kW}$. The simulation is performed with a power of $11 \mathrm{~kW}$. This is due to technical restrictions of many charging points.

A method to prove ecological sustainably is by indicating the amount of saved $\mathrm{CO}_{2}$ emissions. Therefore, it was assumed that conventional resources emit $730 \mathrm{~g} \mathrm{CO}_{2} / \mathrm{kWh}$ and renewable energy sources $40 \mathrm{~g} \mathrm{CO}_{2} / \mathrm{kWh}$ [11]. In Germany the yet-to-be-registered new vehicles emit about $136.4 \mathrm{~g} / \mathrm{km} \mathrm{CO}_{2}$, without considering the emissions to transport and produce conventional fuel. This value will be compared with the well-to-wheel $\mathrm{CO}_{2}$ emissions of electric vehicles without and with the use of the charging management presented in [1] and the prediction based management.

\section{B. Simulation results}

The simulation results with the use of the prediction based charging management are presented in the following passages. The results show how the management system works. The primary optimization factor is the supplied local renewable power (Fig. 4). The second highest influence has the load of the distribution grid. In the two figures 4 and 5 the influence of local renewable energy is shown.

In Fig. 4 it can be seen, that at the current time (dashed line) a peak of local renewable energy is predicted in two hours. In Fig. 5 the predicted signal in two hours (red curve) considers the peak of the local renewable energy, so it increases at the current time (dashed line). The current signal (blue curve) with a much lower amount of renewable energy is also significantly lower, than the signal in two hours. The charging management compares all signals and recognizes that the signal increases. The final signal (cyan curve), which is given to the FEV is set to " 0 " while the predicted signals are higher and the FEV has not to be charged based on the need of mobility. It can also be seen, that the current signal in two hours has a similar curve like the predicted signal. At this moment the current signal is the highest of all signals, so the final signal is set to the current one.

As the figures 4 and 5 show the management reacts to the predicted inputs. This reaction leads to a much higher amount of local renewable energy which is charged into the FEV. In numbers, the management increases the amount from $7 \%$ to $17 \%$ with the prediction based charging system, while the non-prediction based management in [1] was only able to increase the amount to $11 \%$.

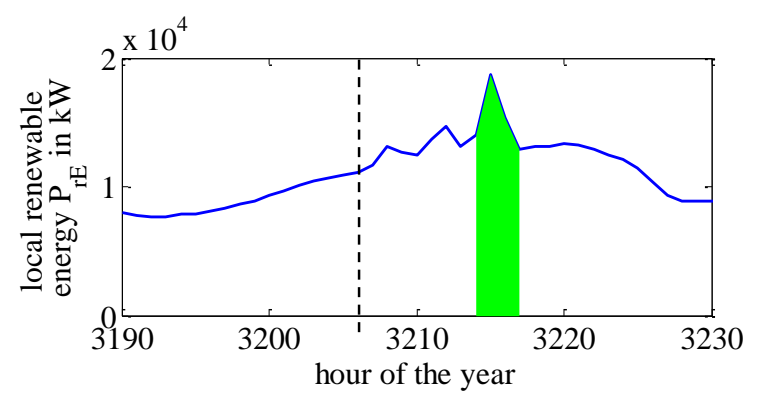

Fig. 4. Time series of local renewable power

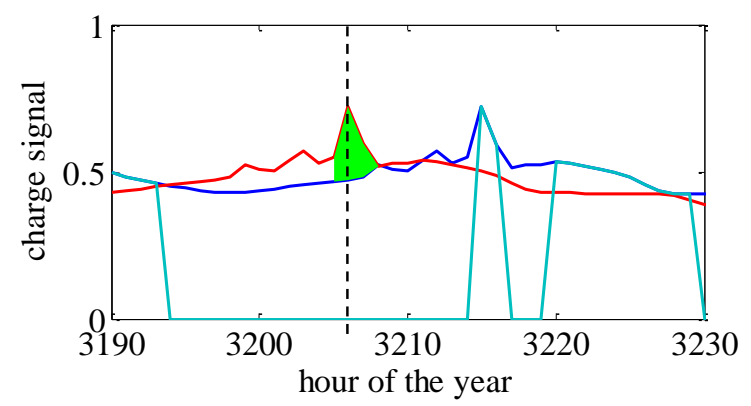

Fig. 5. Time series of the simulated charge signal (blue-current, red-in 2 hours, cyan-final signal)

The comparison of the $\mathrm{CO}_{2}$ emissions shows that electric vehicles are not more ecological sustainable when they are charged without a charging management. With the energy mix in the considered area with the low percentage of renewable energy electric vehicles emit $113 \mathrm{~g} \mathrm{CO}_{2} / \mathrm{km}$, which is only slightly lower than the emission of conventional cars. The charging management presented in [1] can significantly improve the emissions to $103 \mathrm{~g} \mathrm{CO}_{2} / \mathrm{km}$ the prediction based charging management reduces the emission of $\mathrm{CO}_{2}$ to $95 \mathrm{~g} \mathrm{CO}_{2} / \mathrm{km}$ well-to-wheel. 


\section{Conclusions}

This paper described a prediction based charging management for FEV. The optimization focuses on the real time high capacity of local renewable energy in the grid and the load of the distribution grid. The additional challenges of a mobility-on-demand-concept are also considered. The prediction based charging management enhances the former management in [1] to consider non usage times of the FEV and predicted peaks of local renewable energy. The management decides whether the FEV has to be charged or not.

The management, based on the charge signal in [1] was able to increase the usage of local renewable energy from a percentage of $7 \%$ to $11 \%$. The prediction based management made it possible to increase the amount of local renewable energy to $17 \%$. With the increased usage of renewable energy the ecological sustainably treated with the $\mathrm{CO}_{2}$ emissions can be significantly improved. The prediction based charging management reduce the $\mathrm{CO}_{2}$ emissions from $113 \mathrm{~g} / \mathrm{km}$ to $95 \mathrm{~g} / \mathrm{km}$. Additionally the management considers the load of the distribution grid as well as guaranteed permanent mobility for mobility-ondemand-concepts.

\section{Acknowledgement}

This work is one part of the research group "fahrE concepts of multi-modal micro mobility using local renewable energy" and is funded by the European Social Fund.

\section{References}

[1] D. Kühnert, W. Schufft: "Charging management for full electric vehicles (FEV) in the mobility-ondemand-concept "fahrE" using local renewable energy", ICREPQ'13, Bilbao, 2013

[2] Federal Ministry for Economics and Technology; „Verfügbarkeit und Versorgung mit Energierohstoffen“, http://bmwi.de/BMWi/Redaktion $/ \mathrm{PDF} / \mathrm{E} /$ energierohstoffbericht,property=pdf,bereich= bmwi2012,sprache=de,rwb=true.pdf, Berlin, 2006
[3] T. Barker, et al.; "Technical Summary" in: Climate Change 2007: Mitigation. Contribution of Working Group III to the Fourth Assessment Report of the Intergovernmental Panel on Climate Change, United Kingdom and New York, NY, USA: Cambridge University Press, 2007

[4] Federal Ministry for the Environment, Nature Conservation and Nuclear Safety: "Federal Environment Minister Röttgen: 20 percent renewable energies are a great success", http://www.erneuerbareenergien.de/english/current_press_releases/pm/47744 . php. Berlin, 2011

[5] Öko-Institut e.V. on behalf of the Federal Ministry for the Environment, Nature Conservation and Nuclear Safety, „OPTUM: Optimierung der Umweltentlastungspotentiale von Elektrofahrzeugen - Integrierte Betrachtung von Fahrzeugnutzung und Energiewirtschaft" 2011 .

[6] J. Teuscher, A. Götz, W. Schufft: "Electric vehicles and their effects in low-voltage grids", ICREPQ'11, Las Palmas de Gran Canaria, 2011

[7] T. Franke, J. F. Krems: "What drives range preferences in electric vehicle users?" Transport Policy, Volume 30,2013

[8] P. Vortisch, T. Streit, B. Chlond, M. Wirtz, C. Weiß, D. Zumkeller: "Deutsches Mobilitätspanel (MOP) wissenschaftliche Begleitung und erste Auswertungen", KIT Karlsruher Institut für Technologie, Karlsruhe, 2012

[9] H. Hähnel: „Modellierung und Prognose von Globalstrahlungszeitreihen“, Workshop Mathematik in Forschung und Lehre, TU Chemnitz, Marienberg, September 2011

[10] F. Kasten: „Parametrisierung der Globalstrahlung durch Bedeckungsgrad und Trübungsfaktor", Annalen der Meteorologie 20 (1983), S. 49 - 50

[11] H. Herminghaus: „CO2-Vergleich bei der Stromerzeugung", $\quad$ http://www.co2-emissionenvergleichen.de/Stromerzeugung/CO2-VergleichStromerzeugung.html 